\title{
Transcarotid endoaortic balloon occlusion of the stent graft during reintervention on the thoracoabdominal aorta after thoracic endovascular aortic repair
}

\author{
Michele Murzi, MD, Pier Andrea Farneti, MD, Andrea Tognarelli, MD, and Mattia Glauber, MD, Massa, \\ Italy
}

Secondary surgical interventions after thoracic endovascular aortic repair (TEVAR) represent a complex surgical scenario associated with high morbidity and mortality. The main difficulties lie in proximal arterial control and management of the previously implanted endograft. ${ }^{1}$ In this report, we propose a surgical strategy based on transcarotid endoclamping of the stent graft, which allows a safe and effective proximal aortic occlusion during reintervention on the thoracoabdominal aorta after TEVAR, avoiding deep hypothermic circulatory arrest (DHCA) and minimizing the risks of bleeding and aortic injury.

\section{CLINICAL SUMMARY}

A 37-year-old man with a history of TEVAR for type B acute aortic dissection after proximal descending aorta replacement for aortic coarctation repair was admitted to the G. Pasquinucci Heart Hospital for a huge distal thoracic aorta aneurysm $(100 \times 93 \mathrm{~mm})$ caused by severe type $1 \mathrm{~b}$ endoleak (Figure 1). After collegial discussion, a surgical approach was deemed as the only modality to treat the

From the Fondazione G. Monasterio, G. Pasquinucci Heart Hospital, Massa, Italy. Disclosures: Authors have nothing to disclose with regard to commercial support. Received for publication March 4, 2013; revisions received March 26, 2013; accepted for publication April 5, 2013; available ahead of print May 13, 2013.

Address for reprints: Mattia Glauber, MD, G. Pasquinucci Heart Hospital, Adult Cardiac Surgery Department, Via Aurelia Sud, 54100 Massa, Italy (E-mail: glauber@ftgm.it).

J Thorac Cardiovasc Surg 2013;146:481-2 $0022-5223 / \$ 36.00$

Copyright (C) 2013 by The American Association for Thoracic Surgery http://dx.doi.org/10.1016/j.jtcvs.2013.04.003 patient. The procedure was performed with a thoracophrenolaparotomy in the fifth intercostal space with cerebrospinal fluid drainage. The left femoral artery and vein were cannulated for cardiopulmonary bypass. In addition, the left common carotid artery was cannulated through a 10-mm Dacron graft, using a $21 \mathrm{~F}$ Y-shaped arterial cannula specifically designed for endoaortic balloon occluder deployment (EndoReturn Arterial Cannula; Edwards Lifesciences, Irvine, Calif). When the distal portion of the aneurysm was completely mobilized, cardiopulmonary bypass was started through the carotid artery line, and at $32^{\circ} \mathrm{C}$ of nasopharyngeal temperature an endoaortic balloon occluder (EndoClamp Aortic Catheter; Edwards Lifesciences) was inserted and inflated within the proximal portion of the stent graft (Figure 2). Balloon occluder deployment was performed with significant reduction of pump flow and guided by transesophageal echocardiography. In addition, the correct position of the endoaortic balloon was confirmed by the disappearance of the femoral artery pressure wave with the maintenance of the left radial artery wave. The proximal abdominal aorta was clamped proximally to the celiac trunk, and the lower body was perfused via the femoral cannula. The aneurysm was opened, the location of the endoleak was identified, and the distal portion of the endograft was cut and removed. A 24-mm graft (Gelweave; Vascutek, Ltd, Renfrewshire, UK) was placed with a polypropylene running suture to the residual endograft. The new graft was crossclamped, and the balloon occluder was deflated and removed. Finally, the distal anastomosis between the new graft and the proximal abdominal

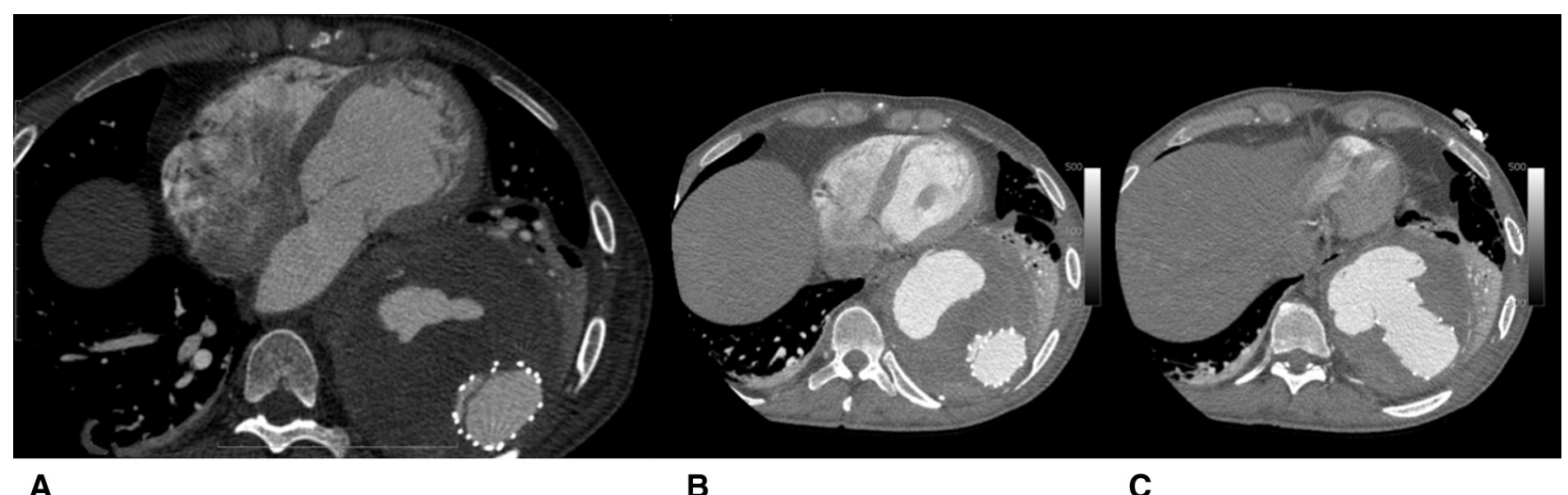

A

B

C

FIGURE 1. Axial computed tomography scans showing the residual type Ib endoleak with reperfusion of the aneurysm sac: (A) mid-descending aorta, (B) distal descending aorta, and (C) proximal abdominal aorta. 


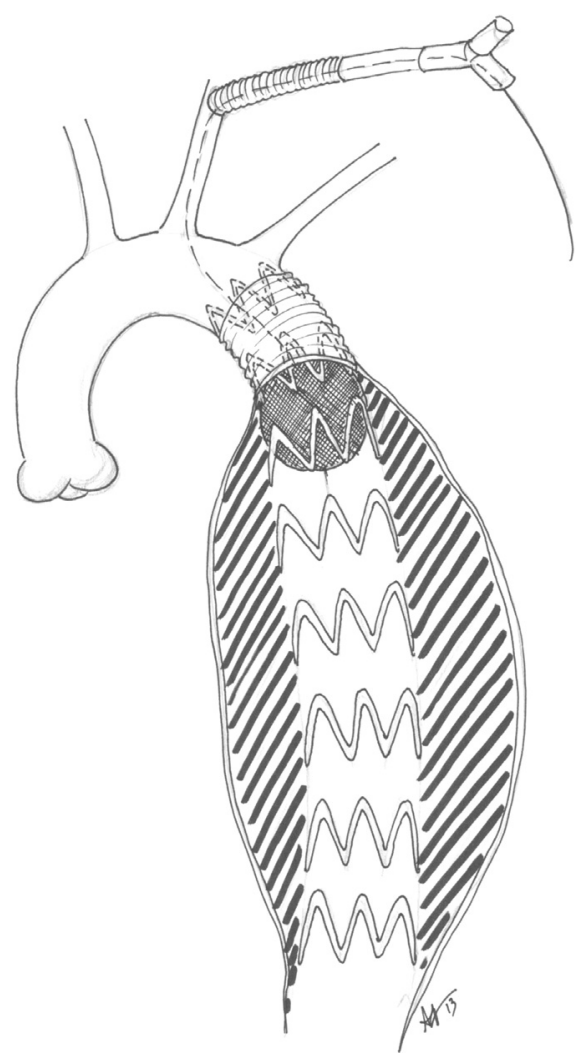

FIGURE 2. Schematic drawing of the procedure shows the endoaortic balloon occluder within the previously implanted stent graft.

aorta was performed. Balloon inflation time was 16 minutes, and crossclamp time was 29 minutes. The postoperative course was uneventful, and the patient was discharged on the 14th postoperative day. At 1-year follow-up, the patient is in good health.

\section{DISCUSSION}

The management of a previously implanted endograft during surgical intervention on the thoracic aorta represents a challenging situation for the surgeon. Indeed, when the stent graft has been released in the proximal thoracic aorta, safe clamping of the aorta above the stent graft may be hazardous, and DHCA is usually required to obtain proximal aorta control. ${ }^{2,3}$ Nevertheless, DHCA has been associated with an increased incidence of coagulopathy and organ dysfunction, mostly related to deeper levels of hypothermia and prolonged periods of extracorporeal circulation. ${ }^{4}$ In addition, hypothermia less than $30^{\circ} \mathrm{C}$ may severely affect the mechanical properties of the stent graft, decreasing its radial expansive force and shrinking the diameter. ${ }^{5}$ In an effort to overcome these problems, we proposed a surgical strategy that achieves complete occlusion of the endograft and allows easier repair of the thoracic aortic aneurysm, avoiding DHCA. Because there is no need for proximal crossclamping, dissection in the area of the proximal descending aorta and left pulmonary artery is avoided, and the risk of massive bleeding is minimized. Releasing the endoballoon in the proximal descending aorta through the left carotid artery is a simple procedure that is facilitated by the blood ejection force of the left ventricle. The rigid structure of the stentgraft offers an ideal surface for efficient occlusion of the aorta with the endoballoon. Moreover, in our experience the use of a balloon occlusion catheter provides a relatively bloodless field and an adequate field of view. Nevertheless, continuous monitoring of the endoballoon position by transesophageal echocardiography and indirect monitoring of eventual displacement are mandatory.

\section{CONCLUSIONS}

This procedure may represent an alternative to obtain safe and effective proximal thoracic aorta control in cases in which proximal aortic clamping cannot be accomplished with standard methods. The need to totally remove the stent graft, as in aortic infections, and the presence of severe atheromatic disease in the aortic arch are contraindications to the use of this technique.

\section{References}

1. Girdauskas E, Falk V, Kuntze T, Borger MA, Schmidt A, Scheinert D, et al. Secondary surgical procedures after endovascular stent grafting of the thoracic aorta: successful approaches to a challenging clinical problem. J Thorac Cardiovasc Surg. 2008;136:1289-94.

2. Szeto WY, Desai ND, Moeller P, Moser GW, Woo EY, Fairman RM, et al. Reintervention for endograft failures after thoracic endovascular aortic repair. J Thorac Cardiovasc Surg. 2013;145:S165-70.

3. Canaud L, Alric P, Gandet T, Albat B, Marty-Ané C, Berthet JP. Surgical conversion after thoracic endovascular aortic repair. J Thorac Cardiovasc Surg. 2011; 142:1027-31.

4. Robich MP, Hagberg R, Schermerhorn ML, Pomposelli FB, Nilson MC, Gendron ML, et al. Hypothermia severely effects performance of nitinol-based endovascular grafts in vitro. Ann Thorac Surg. 2012;93:1223-7.

5. Cooper WA, Duarte IG, Thourani VH, Nakamura M, Wang NP, Brown WM III, et al. Hypothermic circulatory arrest causes multisystem vascular endothelial dysfunction and apoptosis. Ann Thorac Surg. 2000;69:696-702. 